\title{
ReLAInEP
}

\section{CONTROLE E REPOSIÇÃO DE COMPONENTES CRÍTICOS EM UMA EMPRESA DE MONTAGEM DE PLACAS ELETRÔNICAS.}

\author{
Edernice dos Santos ${ }^{1}$ \\ Tamy Cordeiro da Cunha ${ }^{2}$
}

Alessandra G. Souza ${ }^{3}$

\begin{abstract}
RESUMO: Este artigo apresenta um estudo desenvolvido em uma montadora de placas eletrônicas. Para esse estudo foi analisado o fluxo de informações entre o setor comercial, setor de compras e o setor de Planejamento e Controle de Produção. As informações analisadas dizem respeito ao componente Relê 822, o qual é um item denominado "crítico", pois existe apenas um fabricante deste componente no mundo. O Relê 822 faz parte da estrutura do produto "Placa de Bloqueio Progressivo". O objetivo do estudo é auxiliar na tomada decisão sobre a reposição deste componente, buscando reduzir os custos e garantindo que o componente esteja na fábrica em tempo hábil para a produção e entrega dos pedidos. $\mathrm{O}$ estudo realizado revela a necessidade de planejar a reposição do Relê 822 de forma semestral, buscando eliminar problemas relacionados com a falta do componente no mercado, o que poderá aumentar seu custo unitário e de transporte. O fluxo de informações sobre este componente será imprescindível para manter um relacionamento direto e transparente com o cliente, podendo ocorrer à confirmação de datas de entrega e, quando necessário, a negociação de novos prazos em tempo hábil.
\end{abstract}

Palavras-chave: Componente Crítico, Importação, Reposição de materiais, Demanda.

ABSTRACT: This paper presents a study developed in an assembler of electronic boards. For this study, we analyzed the flow of information between the commercial sector, purchasing department and the Planning and Production Control sector. The informationanalyzed concern the relay component 822 , which is an item called "critical" because there is only one manufacturer of this component in the world. The relay 822 is part of the product structure "Locking Plate Progressive". The objective is to assist in making decision on the replacement of this component, seeking to reduce costs and ensuring that the component is in a timely manner at the factory for the production and delivery of applications. The study reveals the need to plan the replacement of the 822 relay semi-annually, seeking to eliminate

\footnotetext{
${ }^{1}$ Pontifícia Universidade Católica do Paraná/PUCPR. edernice@hotmail.com.

${ }^{2}$ Pontifícia Universidade Católica do Paraná/PUCPR. tamyys@ hotmail.com.

${ }^{3}$ Pontifícia Universidade Católica do Paraná/PUCPR. gomes.alessandra@pucpr.br.
}

ReLAInEP - Revista Latino-America de Inovação e Engenharia de Produção, Curitiba, PR, Brasil, v. 3, n. 4, p. 153-169, 2015. 


\section{ReLAInEP}

problems related to the missing component in the market, which may increase your unit cost and transport. The flow of information on this component is essential to maintain a direct and transparent relationship with the client, may occur to confirm delivery dates and, where necessary, negotiating new terms in a timely manner.

Keywords: Critical Component, Import, replacement materials demand.

RESUMEN: Este artículo presenta un estudio desarrollado en una montadora de placas electrónicas. Para este estudio se analizó el flujo de información entre el sector comercial, el departamento de compras y el sector de Planificación y Control de la Producción. La información analizada se refiere a la componente de relé 822, que es un elemento llamado "crítico", porque sólo hay un fabricante de este componente en el mundo. El relé 822 es parte de la estructura del producto "Bloqueo Platte Progresista". El objetivo es ayudar en la toma de decisiones sobre la sustitución de este componente, tratando de reducir los costos y asegurar que el componente es de manera oportuna en la fábrica para la producción y la entrega de aplicaciones. El estudio revela la necesidad de planificar la sustitución del relé de 822 veces al año, tratando de eliminar los problemas relacionados con el componente que falta en el mercado, lo que puede aumentar su costo y la unidad de transporte. El flujo de información sobre este componente es esencial para mantener una relación directa y transparente con el cliente, puede ocurrir que confirmar las fechas de entrega y, en su caso, la negociación de nuevos términos en el momento oportuno.

Palabras-clave: Críticos de componentes, Importación, la demanda de materiales de reemplazo.

\section{INTRODUÇÃO}

As empresas atuais encontram um cenário cada vez mais competitivo, onde o controle de custos e a melhoria da qualidade dos produtos se tornam os diferenciais de maior valor no mercado.

Segundo Dennis (2008), padronizar um processo significa introduzir o conceito de que há um "jeito certo de fazer as coisas", mas existem algumas causas que afetam a manutenção desta padronização, como por exemplo, os problemas de qualidade nos componentes recebidos e a falta dos mesmos. Baseando-se nesta definição é possível dizer que a padronização dos processos produtivos auxilia na manutenção dos padrões de qualidade, tornando o controle de custos e a reposição de materiais o grande desafio das empresas.

ReLAInEP - Revista Latino-America de Inovação e Engenharia de Produção, Curitiba, PR, Brasil, v. 3, n. 4, p. 153-169, 2015. 


\section{ReLAInEP}

Este trabalho demonstra que simples analises podem auxiliar no planejamento de reposição de materiais críticos, em especial neste caso estudado, o componente é o Relê 822, produzido por apenas uma empresa no mundo. Este componente se tornou um item indispensável da estrutura do produto "Placa de Bloqueio Progressivo", sendo um item com a função de maior importância da placa, pois garante a segurança do motorista e do caminhão em que a placa estará instalada.

De acordo com Chopra (2004), durante processos de tomada de decisão, dados históricos - como informações sobre o consumo de produtos em períodos passados - são importantes, pois fornecem informações relacionadas à demanda e permitem traçar séries temporais em um horizonte específico. O principal problema observado na reposição do componente "Relê 822" é planejar a compra e reposição deste componente baseando-se em demandas passadas e previsões de demandas futuras, já que o componente tem um alto custo e um longo lead time tanto para a sua produção como para a sua entrega, decisões como o tipo de transporte a ser utilizado também deverá ser definido. Um bom planejamento aumentará a confiabilidade e a competitividade da empresa perante o mercado.

\section{REVISÃO DE LITERATURA}

Para dar suporte teórico ao artigo em questão, foi realizado um estudo bibliográfico sobre os assuntos que estão relacionados à reposição de materiais, como, por exemplo, a definição de estoques e documentos de importação, entre outros temas.

Conforme mencionado por Lustosa (2008), os estoques representam um importante ativo nas empresas de manufatura e, por isso, devem ser gerenciados de forma eficaz para não comprometerem os resultados da empresa. Atualmente, as melhores práticas de gestão de cadeia de suprimentos passam, inevitavelmente, pela gestão de estoques.

Em termos financeiros é imprescindível à programação de estoques, Lucena e Filho (2002) enfatizam que "existe um custo dos estoques que aumenta os custos operacionais e diminui os lucros, razão por que a boa administração dos mesmos é essencial". Neste contexto, pretende-se analisar como a montadora de placas eletrônicas trabalha com as questões referentes ao planejamento e gestão de estoques do componente Relê 822 para operar de forma eficiente.

ReLAInEP - Revista Latino-America de Inovação e Engenharia de Produção, Curitiba, PR, Brasil, v. 3, n. 4, p. 153-169, 2015. 


\section{ReLAInEP}

O principal foco da empresa, comum a todos os concorrentes, é atender de forma eficiente as necessidades dos clientes, conquistando cada dia uma fatia maior do mercado.

Atender a demanda do mercado é de suma importância para as empresas, que tem como objetivo entregar dentro do prazo estipulado, seus produtos e serviços a seus clientes, atendendo suas exigências, é uma característica que se torna um diferencial competitivo dentro do segmento que atua. As organizações procuram manter a qualidade de seus produtos, e cabe a seus gestores fazerem um estudo prévio para calcular tal demanda, como e quando será necessária a compra de matéria prima, assim como a reposição de materiais. Um problema clássico para da Engenharia de Produção é a determinação do esquema ótimo de renovação do estoque de certa mercadoria (ALVARENGA e NOVAES, 2000).

O principal objetivo da montadora é ter um planejamento para a reposição deste relê, que apesar de definido como um componente crítico poderá ser reposto em tempo hábil, mantendo as entregas aos clientes de acordo com as suas solicitações informadas em previsões e confirmadas com as ordens de compra. Estabilizando a reposição deste material, com o investimento em um estoque de segurança deste componente, a montadora poderá focar em conquistar o mercado com um produto desenvolvido pela própria empresa, tendo lucro máximo com a comercialização do mesmo. Para Dias (2005), um dos objetivos de uma empresa que vise o lucro é maximizar o retorno sobre o capital investido, sejam em fábricas, equipamentos, financiamentos de vendas, reserva de caixa ou em materiais e estoques. Para o autor, o dinheiro investido em estoques é importante facilitador para a produção e o bom atendimento das vendas.

Sob o ponto de vista operacional, o estoque serve para amortecer as diferenças entre os fluxos da empresa de entrada e saída de materiais. Sob o ponto de vista financeiro, o estoque é um investimento e tem custos para mantê-lo na empresa, tais como perdas, manutenção, armazenagem, estoque ainda deve proporcionar retorno de capital. Sabe-se que a manutenção dos estoques custa dinheiro, as empresas devem reduzir os estoques ao máximo sem prejudicar o nível de serviço, (NOVAES e ALVARENGA, 2000). Fica clara a importância do gerenciamento de estoques, o estoque é um importante elemento na cadeia de suprimentos e pode alterar a eficiência das empresas se não for bem gerenciado (CHOPRA e MEINDL, 2003).

ReLAInEP - Revista Latino-America de Inovação e Engenharia de Produção, Curitiba, PR, Brasil, v. 3, n. 4, p. 153-169, 2015. 


\section{ReLAInEP}

Existem vários métodos para controlar estoques e gerenciar a reposição de materiais, Bertaglia (2003) afirma que a compreensão dos objetivos estratégicos da existência do gerenciamento dos estoques é fundamental para definir metas, tipos de estoque e forma como eles afetam as organizações em suas atividades produtivas de relacionamento com o mercado. Estoques possuem custos, que são importantes para a determinação da política de estoque: custos de aquisição, custos de manutenção e custos de falta de estoques (BALLOU, 2006). A gestão de estoques é uma atividade cada vez mais foco de engenheiros, administradores e todas as pessoas envolvidas diretamente no processo produtivo de empresas de produtos e serviços, ela deve coordenar a movimentação de suprimentos com a exigência de operação, prover o material certo, no momento certo com o custo mínimo (BALLOU, 1993).

Ao conseguir-se otimizar os investimentos em estoques, com negociações e estratégias, dimensionamento dos estoques e projetos de sistemas de distribuição, pode-se ter redução de custos e aumento no lucro (POZO, 2004). Seguindo esse raciocínio, a montadora tem nessa definição o seu maior objetivo, atendimento no prazo com a maior redução de custo possível.

Atualmente as empresas buscam utilizar as informações aliadas à gestão de estoques, pois pode ser considerado um fator de grande importância na cadeia de suprimentos, diante deste contexto, Chopra e Meindl (2003) afirmam que um dos elementos desta política é a previsão da demanda, considerada peça importante para entendimento e apoio aos processos de decisão e planejamento dos estoques feito pela gerência. Essa área tem a função de administrar todos os materiais da empresa, dos estoques às instalações, formas e locais de armazenagem em locais seguros e de fácil acesso. Nos dias atuais cada vez mais se houve falar em otimização de estoques, como modo de aumento de eficiência. Os objetivos do gerenciamento de estoques são maximizar os recursos da empresa e fornecer um nível satisfatório de serviço ao cliente ou consumidor.

O gerenciamento de estoques com qualidade garante um bom nível de serviço, que é o resultado de todos os esforços logísticos da empresa no atendimento dos pedidos dos clientes (BALLOU, 1993). O controle de estoques envolve as tarefas de coordenação de fornecedores, condições físicas, armazenamento, distribuição e registro das existências de todas as mercadorias (GURGEL, 2000). O trade-off central geralmente se dá entre eficiência e flexibilidade: o aumento da flexibilidade geralmente exige que a empresa eleve o seu estoque de segurança e mantenha capacidade de reserva para atender a demanda inesperada, ao passo

ReLAInEP - Revista Latino-America de Inovação e Engenharia de Produção, Curitiba, PR, Brasil, v. 3, n. 4, p. 153-169, 2015. 


\section{ReLAInEP}

que o aumento da eficiência exige que essas duas reservas sejam reduzidas ao mínimo (TAYLOR, 2009).

Como o objeto do nosso estudo é indicar a melhor maneira de reposição de um componente importado, se faz necessário uma rápida abordagem, sobre importações, procedimentos e custos, deve - se verificar a necessidade de importar, se o mercado nacional tem disponibilidade para fornecer esse componente ou o seu similar. Alguns fatores importantes que levam a prática de importação desse item é a falta de fornecedores nacionais e o preço do produto.

A importação é realizada, como um processo de compra organizacional, que consiste no processo de decisão para estabelecer "a necessidade de comprar produtos e serviços e então identificar, avaliar e escolher entre marcas e fornecedores alternativos", segundo Kotler (2000).

Para Rosembloom (2002), o transporte é o componente que responde pela maior porcentagem do custo total da logística. Ballou (2001) complementa que o transporte pode ser responsável por um terço a dois terços dos custos logísticos totais. As taxas de linhas de transporte são baseadas em distância e volume de embarque (BALLOU, 2001). Lopez (2000) afirma que existem três etapas de transporte: pré-transporte (frete interno na origem); transporte internacional (deslocamento entre dois países); pós-transporte (frete interno de destino).

\section{METODOLOGIA}

O objetivo geral desta pesquisa é contribuir para a importação de um determinado item critico, auxiliando no controle e planejamento da reposição deste item. Focando no aumento da eficiência do planejamento e otimização do controle da gestão da cadeia de suprimentos, capazes de desenvolverem o processo, consequentemente o produto, convergindo assim para a melhoria da qualidade da produção e monitoramento da cadeia de suprimentos.

Este artigo tem uma abordagem qualitativa, com a utilização de ferramentas simples, disponíveis a todas as empresas atuais, que buscam sinalizar e relacionar dados com o objetivo de identificar as melhores opções de planejamento e controle de estoque de tal componente.

ReLAInEP - Revista Latino-America de Inovação e Engenharia de Produção, Curitiba, PR, Brasil, v. 3, n. 4, p. 153-169, 2015. 


\section{ReLAInEP}

Para auxiliar na busca de informações foi utilizado o questionário "Informações Iniciais", detalhado no anexo I.

\section{APRESENTAÇÃO DOS DADOS}

\subsection{A empresa}

A empresa analisada é uma montadora de placas eletrônicas que está a mais de dez anos no mercado e que pode ser classificada como uma empresa de pequeno porte, pois possui cerca de 50 colaboradores e um faturamento de até $\mathrm{R} \$ 3.600 .000,00$ por ano. A empresa está instalada no bairro Capão Raso na cidade de Curitiba - PR, e possui uma filial na cidade de Pato Branco no interior do Estado do Paraná.

Seu portfólio possui mais de 50 produtos dentre os quais, a Placa de Bloqueio Progressivo, o Sensor de Desengate, o carregador de baterias e os conversores se destacam, pois, foram desenvolvidos pela montadora. Devido a esse variado portfólio, atende os mercados de Energia, Gás e Água, Rastreamento Veicular, Ventilação, Displays, Conversores Ethernet Serial, Sistemas de Segurança Bancário e Residencial, Equipamentos Odontológicos, entre outros. Possui certificação ISO 9001:2008 em todos os seus procedimentos operacionais; desenvolvimento, produção e comercialização de sistemas eletrônicos.

Atualmente as vendas são efetuadas tanto no varejo como no atacado. Quanto ao processo produtivo, o mesmo pode ser classificado de duas formas:

- Industrialização: quando o cliente fornece todos os componentes da estrutura da placa e a montadora realiza apenas o serviço de montagem e testes;

- Produção: quando a montadora fica responsável pela compra e administração dos componentes, montando e testando as placas para então serem comercializadas.

A empresa mantém estoque de produto acabado e de materiais. Toda produção é definida a partir de uma demanda, confirmada por pedidos e/ou previsões dos clientes. Contando com uma equipe altamente qualificada, a montadora oferece suporte ao desenvolvimento e reengenharia de produtos.

ReLAInEP - Revista Latino-America de Inovação e Engenharia de Produção, Curitiba, PR, Brasil, v. 3, n. 4, p. 153-169, 2015. 


\section{ReLAInEP}

\subsection{Dados do processo de importação do componente analisado}

A Placa de Bloqueio Progressivo é um produto desenvolvido pela montadora que a principio realizou o projeto buscando solucionar a necessidade de um de seus clientes. Hoje a placa pode ser montada com o comprimento do chicote conforme a necessidade do cliente, mas todas as outras características do produto se mantêm sem alterações. Analisando todo o processo de montagem desta placa, o tempo médio de montagem e testes é de quinze minutos. Devido ao longo lead time de entrega dos componentes críticos, é mantido um estoque de segurança de $20 \%$ da previsão de demanda de produtos acabados. Com a nova analise de reposição do Relê 822, pretende-se eliminar os estoques de segurança de produtos acabados, atendendo as solicitações mensais e mantendo apenas o Relê 822 em estoque.

O layout da placa não sofre alterações periódicas, o que se estuda pela engenharia de produtos é a homologação de um componente similar ao Relê 822, que tem maior disponibilidade no mercado e um preço mais acessível. O processo de homologação de um novo componente é um processo longo, em média, para a aprovação de testes de bancada e testes a campo, demora mais de um ano.

O Relê 822 é um componente de montagem SMD, Surface Mount Device, componente que podemos definir como "dispositivo de montagem de superfície". Este componente tem a função principal da placa, função esta relacionada ao bloqueio progressivo do funcionamento do veículo, não permitindo que haja um bloqueio imediato do motor de um caminhão o que poderia causar um acidente. Cada placa tem um Relê 822 em sua estrutura, devido à importância deste componente, a placa só poderá ser testada quando o componente estiver soldado na posição correta da estrutura.

O Relê 822 é fabricado por apenas uma indústria na Suíça, o qual tem um distribuidor chinês, responsável pela distribuição aos revendedores e indústrias em varias cidades ao redor do mundo. Um dos principais revendedores está em Chicago, nos Estados Unidos, e é o fornecedor atual da montadora.

Em paralelo ao trabalho de compra do componente é realizada a pesquisa de novos fornecedores. O site do fabricante suíço lista os contatos dos revendedores cadastrados, mas algumas tentativas de importação com novos fornecedores identificaram-se que em muitos

ReLAInEP - Revista Latino-America de Inovação e Engenharia de Produção, Curitiba, PR, Brasil, v. 3, n. 4, p. 153-169, 2015. 


\section{ReLAInEP}

casos há a comercialização do Relê 822 falsificados, o que dificultou o cadastramento de novos fornecedores.

A possibilidade de compra diretamente do fabricante só será possível quando a demanda for superior a 10.000 Relês por mês. Já o distribuidor chinês solicita uma previsão de demanda semestral, para que tenha em estoque os relês evitando que seja necessário aguardar o lead time de fabricação que é de quatro semanas, com uma programação de no mínimo 2.000 componentes por mês.

Atualmente a compra deste componente é realizada com o fornecedor americano, que não exige uma quantidade mínima de compra, mas também não garante o atendimento no prazo acordado inicialmente, o que está causando muitos atrasos. Como este revendedor comercializa outros componentes eletrônicos, a exigência para a compra está relacionada a um valor mínimo para fatura, podendo adquirir outros componentes para fechar o valor total.

Para este fornecedor as ordens de compra são disparadas 20 dias antes do dia programado para o inicio da montagem das placas, mas caso não tenha material em estoque o prazo se estende para 70 dias. Para todas as compras é utilizado o transporte aéreo, onde um agente de cargas, contratado pela montadora, consolida todas as compras realizadas em determinado período com diferentes fornecedores, para que seja realizado e cobrado apenas um frete.

$\mathrm{Na}$ formação do preço do componente estão inclusos os custos de transporte até o ponto de entrega para o agente de cargas da origem, encargos relativos à carga, descarga e manuseio, custo de seguro, além do efetivo valor da mercadoria.

No caso da montadora, existe a contratação de um agente aduaneiro, empresa responsável por todos os tramites de importação. Na origem os agentes de carga programam os voos, enviam a declaração de importação para que seja traduzida, com o objetivo de adiantar o processo de desembaraço no Brasil, e fazem a consolidação das cargas. Nos casos de falsificação de componentes, foram os agentes aduaneiros que suspeitaram que algo poderia estar em desacordo, enviando fotos e documentos para que a montadora analise e autorize o embarque ou devolução dos componentes.

O documento norteador do despacho aduaneiro é a Declaração de Importação (DI), que deverá conter as informações gerais, que incluem importador, transporte, carga e pagamento;

ReLAInEP - Revista Latino-America de Inovação e Engenharia de Produção, Curitiba, PR, Brasil, v. 3, n. 4, p. 153-169, 2015. 


\section{ReLAInEP}

e as específicas, chamadas de adição, onde constam fornecedor, valor aduaneiro, tributos e câmbio.

O despacho aduaneiro é o processo de liberação ou desembaraço da mercadoria, que se inicia pelo registro da DI no Siscomex (Sistema Integrado de Comércio Exterior). O procedimento só poderá ser iniciado após a chegada da mercadoria na unidade da receita Federal onde será processado. Estão autorizados a cuidar do despacho aduaneiro o próprio importador ou seu despachante aduaneiro. Após o preenchimento da DI através do Siscomex, o importador deverá transmitir a DI para o computador central do Serpro (Serviço Federal de Processamento de Dados) para conferência e registro dos dados.

Depois da recepção, os documentos seguem para a parametrização, onde serão analisados conforme o canal que forem enviados. Abaixo segue a descrição resumida de cada canal:

- Canal verde: a carga é liberada automaticamente, sem conferência física ou documental;

- Canal amarelo: é feita a conferência documental da operação;

- Canal vermelho: a carga é submetida à conferência documental, física e analise do valor aduaneiro.

Concluída essa fase, a autoridade aduaneira registra o desembaraço da mercadoria no Siscomex e emite o Comprovante de Importação (CI), autorizando a retirada da mercadoria pelo importador.

\section{ANÁLISE DOS DADOS}

\subsection{As demandas}

Analisando as vendas da Placa de Bloqueio Progressivo nos 12 meses anteriores, é possível verificar, na tabela 1 - Demanda x períodos que segue na página seguinte, que a venda do produto está em crescimento:

O gráfico 1 abaixo ilustra esse crescimento no mercado. 


\section{ReLAInEP}

Tabela 1- Demanda x períodos

\begin{tabular}{cccc}
\hline Período & Demanda & Período & Demanda \\
\hline Junho/12 & 470 & Dezembro/12 & 1.450 \\
Julho/12 & 720 & Janeiro/13 & 1.500 \\
Agosto/12 & 980 & Fevereiro/13 & 1.500 \\
Setembro/12 & 1.050 & Março/13 & 1.800 \\
Outubro/12 & 1.100 & Abril/13 & 1.950 \\
\hline
\end{tabular}

Fonte: Elaborado pelo autor

Gráfico 1. Crescimento do mercado.

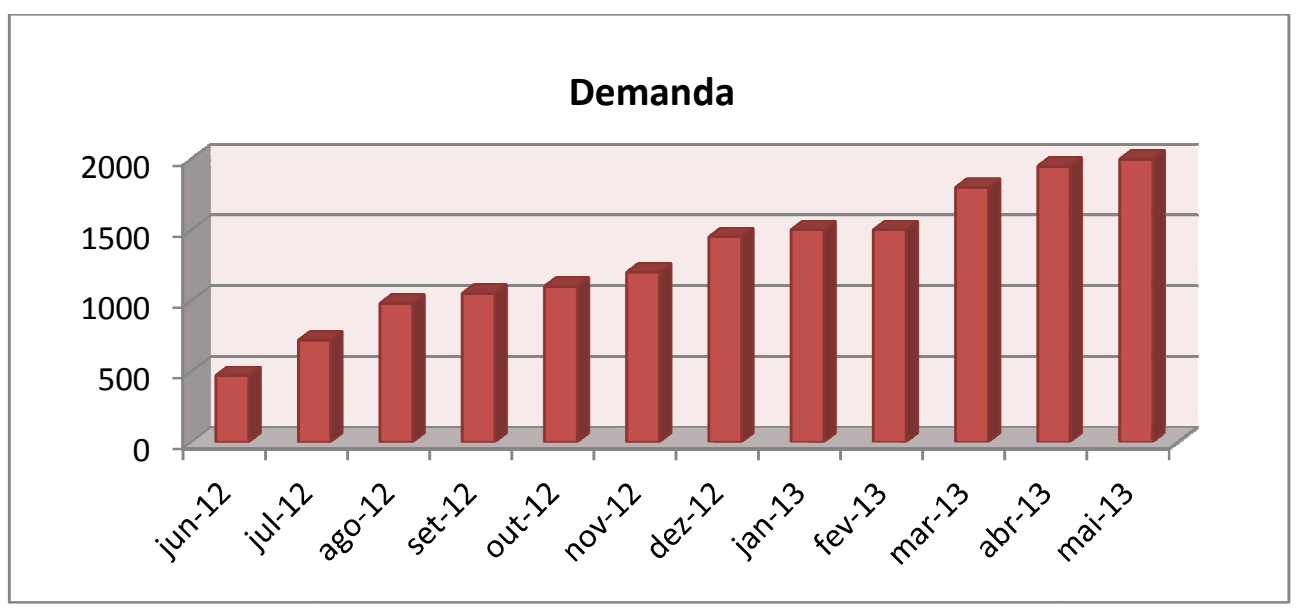

Fonte: Elaborado pelo autor

Em alguns meses existiu a necessidade de aumento dos pedidos de alguns clientes, mas não foi possível atender, pois a montadora tinha os Relês 822 como um limitador de novos pedidos. Devido a esses fatos, solicitou-se aos clientes que realizassem um planejamento apontando quanto e quando precisariam das placas. Através de um acordo comercial, foram programadas as novas demandas, sendo que para os primeiros seis meses seriam demandas confirmadas com ordens de compra e para o segundo semestre seriam demandas baseadas em previsões.

Apesar de pequenas variações durante o primeiro semestre a quantidade total de placas será de 3.000 placas por mês.

\subsection{Frete}

Apesar de pequenas variações durante o primeiro semestre a quantidade total de placas será de 3.000 placas por mês. O levantamento das informações relacionadas aos custos de 


\section{ReLAInEP}

frete será de grande importância e estão detalhadas na planilha da próxima página, Tabela 2 Custos relacionados ao frete.

O tipo de frete escolhido estará relacionado com a redução de custos para a aquisição do Relê 822, também terá relação direta com a data limite para a emissão da ordem de compra, com o objetivo de garantir a chegada do componente em tempo hábil.

O custo do frete terá relação direta com o peso total dos componentes e a ocupação em metros cúbicos.

$\mathrm{O}$ transporte aéreo, apesar de mais caro, tem um tempo de entrega de 15 dias. O transporte marítimo tem o lead time de 35 dias, em contrapartida apresenta um custo bastante reduzido quando comparado ao aéreo. Neste caso o custo do transporte marítimo foi menor do que o custo do frete aéreo atual, com origem nos Estados Unidos, que gira em torno de R\$ $2.000,00$.

Tabela 2. Custos relacionados ao frete.

\begin{tabular}{|c|c|c|c|c|}
\hline \multicolumn{5}{|c|}{ Frete } \\
\hline Peso (kg) & 67 & & & \\
\hline Metro cúbico* & 0,169 & & & \\
\hline Valor (US\$) & 37000 & & & \\
\hline Câmbio & 2,07 & & & \\
\hline \multicolumn{5}{|l|}{ Taxas (US\$) } \\
\hline Aéreo & & Marítimo & & \\
\hline EXW & 298 & EXW & 278 & \\
\hline Frete & 834,15 & Frete** & 75 & 12,675 \\
\hline FSS & 147,4 & Desconsolidação & 120 & \\
\hline SSC & 13,4 & & & \\
\hline Coleta & 1110 & Total 1 (US\$) & 473 & \\
\hline Documentos & 45 & Total $1(\mathrm{R} \$)$ & 979,11 & \\
\hline \multirow[t]{2}{*}{ Desconsolidação } & 60 & & & \\
\hline & & THC*** & 150 & 7,605 \\
\hline Total (US\$) & 2507,95 & Desova*** & 150 & 7,605 \\
\hline \multirow[t]{5}{*}{ Total (R\$) } & 5191,46 & $\mathrm{~B} / \mathrm{L}$ & 180 & \\
\hline & & Siscarga & 50 & \\
\hline & & ISPS & 25 & \\
\hline & & Total $2(\mathrm{R} \$)$ & 555 & \\
\hline & & Total 1+2 (R\$) & 1534,11 & \\
\hline
\end{tabular}

*Metro cúbico ou tonelagem: o que for maior.

** A célula em amarelo é o valor calculado, mas o valor mínimo é US\$ 75,00.

*** Mínimo R\$ 150,00, máximo R\$320,00.

Fonte: Elaborado pelo autor.

ReLAInEP - Revista Latino-America de Inovação e Engenharia de Produção, Curitiba, PR, Brasil, v. 3, n. 4, p. 153-169, 2015. 


\section{ReLAInEP}

\subsection{Planejamento de compras para o próximo ano}

As necessidades do Relê 822 são constantes durante o ano, à base de 3.000 unidades por mês. Os custos de manutenção de Estoque (CME) por unidade é de R $\$ 0,05$ ao mês. O Relê 822 apresenta um preço sazonal, conforme mostrado na tabela 3 abaixo. O gráfico 2 ao lado, ilustra a variação dos preços deixando de forma mais visível os meses mais críticos, que poderão ser antecipados.

Tabela 3. Preços

\begin{tabular}{c|c}
\hline Periodo & Preço \\
\hline jun/14 & $\mathrm{R} \$ 76,00$ \\
\hline jul/14 & $\mathrm{R} \$ 75,00$ \\
\hline ago/14 & $\mathrm{R} \$ 75,00$ \\
\hline set/14 & $\mathrm{R} \$ 74,00$ \\
\hline out/14 & $\mathrm{R} \$ 72,00$ \\
\hline nov/14 & $\mathrm{R} \$ 72,00$ \\
\hline dez/14 & $\mathrm{R} \$ 70,00$ \\
\hline jan/15 & $\mathrm{R} \$ 76,00$ \\
\hline fev/15 & $\mathrm{R} \$ 89,00$ \\
\hline $\mathrm{mar} / 15$ & $\mathrm{R} \$ 75,00$ \\
\hline abr/15 & $\mathrm{R} \$ 74,00$ \\
\hline mai/15 & $\mathrm{R} \$ 72,00$ \\
\hline
\end{tabular}

Fonte: Elaborado pelo autor.

Gráfico 2. Variação de preços.

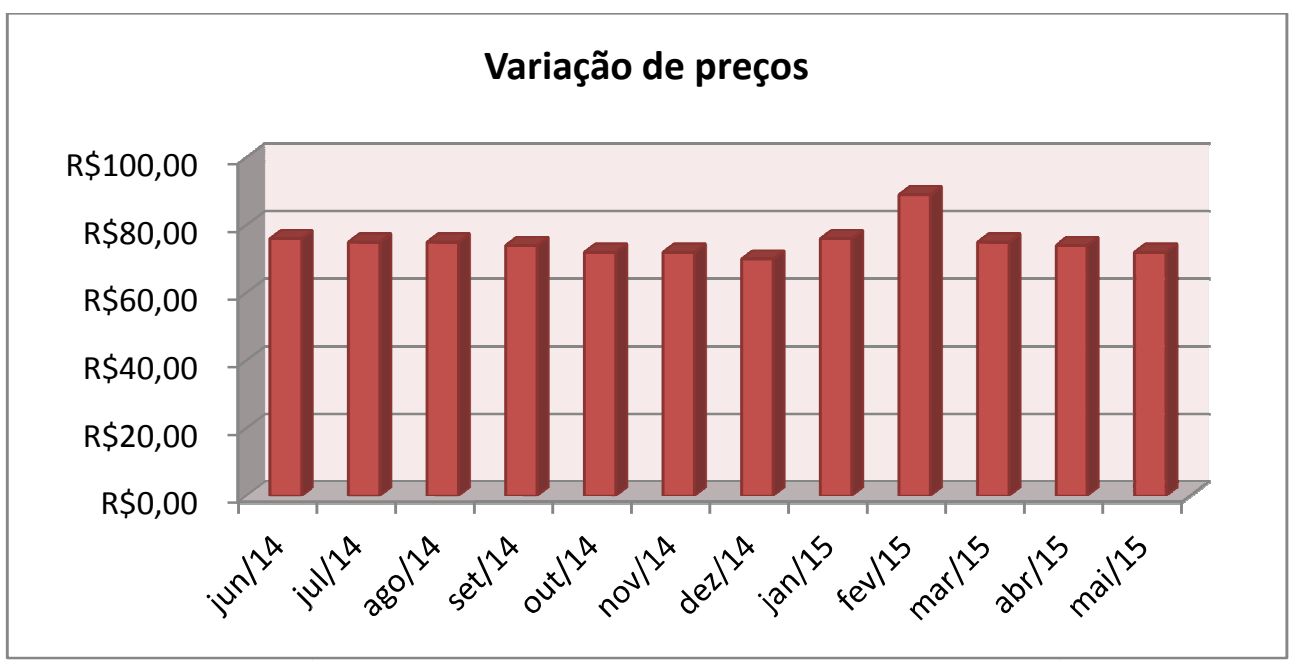

Fonte: Elaborado pelo autor.

Baseando-se nos custos do componente detalhados acima, podemos analisar qual é a melhor forma de aquisição do Relê 822, verificando se as compras antecipadas resultarão ou

ReLAInEP - Revista Latino-America de Inovação e Engenharia de Produção, Curitiba, PR, Brasil, v. 3, n. 4, p. 153-169, 2015. 


\section{ReLAInEP}

não na redução dos custos.

As compras antecipadas apresentam um custo total menor do que se as ordens de compra fossem enviadas conforme as programações mensais, conforme esperado devido à aquisição em quantidades maiores.

Adicionando a quantidade de fretes necessários e os seus respectivos custos, é possível definir os custos totais para a programação anual. A planilha seguinte, tabela 4, detalha toda esta analise.

Tabela 4. Análise

\begin{tabular}{|c|c|c|c|c|c|}
\hline Período & Preço & Estritamente & Ant. 2 meses & Ant. 3 meses & Ant. 6 meses \\
\hline jun/13 & $\mathrm{R} \$ 25,00$ & $\mathrm{R} \$ 75.000,00$ & $\mathrm{R} \$ 75.000,00$ & $\mathrm{R} \$ 75.000,00$ & $\mathrm{R} \$ 75.000,00$ \\
\hline jul/13 & $\mathrm{R} \$ 25,00$ & $\mathrm{R} \$ 75.000,00$ & $\mathrm{R} \$ 75.000,00$ & $\mathrm{R} \$ 75.000,00$ & $\mathrm{R} \$ 75.000,00$ \\
\hline $\mathrm{ago} / 13$ & $\mathrm{R} \$ 24,00$ & $\mathrm{R} \$ 72.000,00$ & $\mathrm{R} \$ 72.000,00$ & $\mathrm{R} \$ 72.000,00$ & $\mathrm{R} \$ 72.000,00$ \\
\hline set/13 & $\mathrm{R} \$ 24,00$ & $\mathrm{R} \$ 72.000,00$ & $\mathrm{R} \$ 72.000,00$ & $\mathrm{R} \$ 72.000,00$ & $\mathrm{R} \$ 72.000,00$ \\
\hline out $/ 13$ & $\mathrm{R} \$ 22,00$ & $\mathrm{R} \$ 66.000,00$ & $\mathrm{R} \$ 66.000,00$ & $\mathrm{R} \$ 66.000,00$ & $\mathrm{R} \$ 66.000,00$ \\
\hline nov/13 & $\mathrm{R} \$ 22,00$ & $\mathrm{R} \$ 66.000,00$ & $\mathrm{R} \$ 66.000,00$ & $\mathrm{R} \$ 66.000,00$ & $\mathrm{R} \$ 66.000,00$ \\
\hline dez/13 & $\mathrm{R} \$ 20,00$ & $\mathrm{R} \$ 60.000,00$ & $\mathrm{R} \$ 120.000,00$ & $\mathrm{R} \$ 180.000,00$ & $\begin{array}{c}\mathrm{R} \$ \\
360.000,00\end{array}$ \\
\hline $\mathrm{jan} / 14$ & $\mathrm{R} \$ 22,00$ & $\mathrm{R} \$ 66.000,00$ & ------ & ------ & ------ \\
\hline fev/14 & $\mathrm{R} \$ 26,00$ & $\mathrm{R} \$ 78.000,00$ & $\mathrm{R} \$ 156.000,00$ & ------ & ------ \\
\hline mar/14 & $\mathrm{R} \$ 27,00$ & $\mathrm{R} \$ 81.000,00$ & ------ & $\mathrm{R} \$ 243.000,00$ & ------ \\
\hline $\mathrm{abr} / 14$ & $\mathrm{R} \$ 28,00$ & $\mathrm{R} \$ 84.000,00$ & $\mathrm{R} \$ 168.000,00$ & ------ & ------ \\
\hline mai/14 & $\mathrm{R} \$ 28,00$ & $\mathrm{R} \$ 84.000,00$ & ----- & ------ & ----- \\
\hline \multicolumn{2}{|c|}{ Subtotal } & $\mathrm{R} \$ 879.000,00$ & $\mathrm{R} \$ 870.000,00$ & $\mathrm{R} \$ 849.000,00$ & $\begin{array}{c}\mathrm{R} \$ \\
786.000,00\end{array}$ \\
\hline \multicolumn{2}{|c|}{ CME } & $\mathrm{R} \$ 75,00$ & $\mathrm{R} \$ 112,50$ & $\mathrm{R} \$ 150,00$ & $\mathrm{R} \$ 262,50$ \\
\hline \multicolumn{2}{|c|}{ TOTAL } & $\mathrm{R} \$ 879.075,00$ & $\mathrm{R} \$ 870.112,50$ & $\mathrm{R} \$ 849.150,00$ & $\begin{array}{c}\mathrm{R} \$ \\
786.262,50\end{array}$ \\
\hline \multicolumn{2}{|c|}{ TRANSPORTE AÉREO } & $\mathrm{R} \$ 62.297,52$ & $\mathrm{R} \$ 46.723,14$ & $\mathrm{R} \$ 41.531,68$ & $\mathrm{R} \$ 36.340,22$ \\
\hline \multicolumn{2}{|c|}{$\begin{array}{c}\text { TOTAL+FRETE } \\
\text { AEREO }\end{array}$} & $\mathrm{R} \$ 941.372,52$ & $\mathrm{R} \$ 916.835,64$ & $\mathrm{R} \$ 890.681,68$ & $\begin{array}{c}\mathrm{R} \$ \\
822.602,72\end{array}$ \\
\hline \multicolumn{2}{|c|}{ TRANSP. MARITIMO } & $\mathrm{R} \$ 18.409,32$ & $\mathrm{R} \$ 13.806,99$ & $\mathrm{R} \$ 12.272,88$ & $\mathrm{R} \$ 10.738,77$ \\
\hline \multicolumn{2}{|c|}{ TOTAL+FRETE } & $\mathrm{R} \$ 897.484,32$ & $\mathrm{R} \$ 883.919,49$ & $\mathrm{R} \$ 861.422,88$ & $\mathrm{R} \$$ \\
\hline
\end{tabular}

ReLAInEP - Revista Latino-America de Inovação e Engenharia de Produção, Curitiba, PR,

Brasil, v. 3, n. 4, p. 153-169, 2015. 


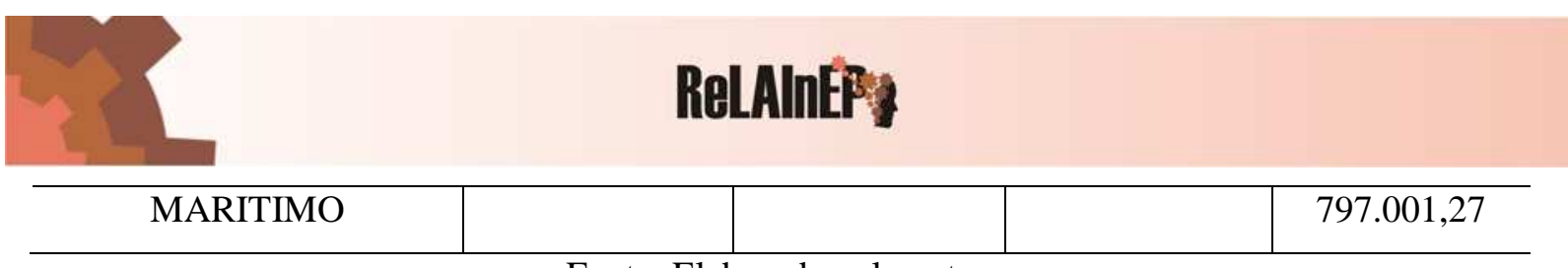

Fonte: Elaborado pelo autor.

\section{CONCLUSÕES}

Este artigo teve o propósito de demonstrar que simples ferramentas, como as planilhas e gráficos, podem auxiliar no planejamento da reposição do Relê 822 definido como um item crítico, devido ao seu alto custo, longo lead time para produção e entrega no Brasil. Neste sentido foram ressaltados alguns pontos positivos e negativos, bem como apresentadas algumas soluções alternativas para a análise dos dados coletados.

Os aspectos positivos relacionam-se com o fluxo e fidelidade das informações, apresentando custos e prazos reais; com a definição da demanda a possibilidade de programação relacionada à redução de custos aumentou, diminuindo a preocupação com os prazos de entrega, prazos estes que não eram foco principal do problema sugerido no artigo.

Em contrapartida, fazer uma programação de compras para o ano seguinte se torna um problema quando esta programação será baseada em demandas passadas e previsões de compras futuras. Este problema foi solucionado buscando estabelecer uma relação de parceria com os principais clientes, onde os setores comerciais de ambas as empresas fizeram um acordo e definiram os pedidos dos próximos períodos.

Esta parceria se estendeu ao fornecedor chinês, que se dispôs a programar o seu estoque para atender a programação da montadora, reduzindo a espera pela fabricação do Relê 822, estipulando um novo prazo de entrega de apenas 35 dias utilizando o transporte marítimo, sendo menor do que o prazo médio de 45 dias oferecido pelo fornecedor atual.

As etapas elaboradas no artigo serviram como uma sequencia de passos, demonstrando que com uma demanda definida, é possível levantar os custos relacionados ao transporte do material, com origens nos novos possíveis fornecedores. Definindo o fornecedor e os preços que serão praticados é possível analisar qual a melhor forma de compra do componente.

Como conclusão podemos dizer que, no problema levantado para analise neste artigo a melhor opção para aquisição do Relê 822 será a compra programada de 3.000 unidades por mês, antecipando seis meses as compras a partir do mês de janeiro e utilizando o transporte marítimo. Disparar as ordens de compra 35 dias antes da programação de montagem da placa na empresa garantirá que o componente esteja na montadora em tempo hábil, entregando os

ReLAInEP - Revista Latino-America de Inovação e Engenharia de Produção, Curitiba, PR, Brasil, v. 3, n. 4, p. 153-169, 2015. 


\section{ReLAInEP}

pedidos nos prazos acordados. Como sugestão principal, podemos ressaltar que um planejamento financeiro, baseado nas informações detalhadas no artigo, poderá resultar na redução de custos totais e a garantia de chegada do componente na empresa.

\section{REFERÊNCIAS}

ALVARENGA, A.; NOVAES, A. Logística Aplicada - Suprimento e Distribuição Física. São Paulo: Edgard Blücher, 2000.

BALLOU, R. H. Gerenciamento da cadeia de suprimentos / Logística empresarial. Porto Alegre: Bookman, 2006.

BALLOU, R. H. Gerenciamento da Cadeia de Suprimentos: planejamento, organização e logística empresarial. Tradução: Elias Pereira. 4a ed. Porto Alegre: Bookman, 2001.

BALlOU, R. H. Logística Empresarial: Transporte, Administração de Materiais e Distribuição Física. São Paulo: Atlas, 1993.

BERTAGLIA, P. Logística e gerenciamento da cadeia de abastecimento. São Paulo, 2003. CHOPRA, Sunil.; MEINDL, Peter. Gerenciamento da cadeia de suprimentos: estratégia, planejamento. São Paulo: Prentice-Hall, 2003.

CHOPRA, Sunil.; MEINDL, Peter. Gerenciamento da cadeia de suprimentos: estratégia, planejamento e operação. São Paulo: Pearson Education Brasil, 2004.

DENNIS, Pascal. Produção Lean Simplificada: um guia para entender o sistema de produção mais poderoso do mundo. Porto Alegre: Bookman, 2008.

DIAS, M. Administração de materiais. São Paulo: Atlas, 2005.

GURGEL, F. Logística industrial. São Paulo: Atlas, 2000.

KOTLER, Philip. Administração de Marketing: a edição do novo milênio. Tradução:

Bazán Tecnologia e Linguística. São Paulo: Prentice Hall, 2000.

LOPEZ, José Manoel Cortiñas. Os Custos Logísticos do Comércio Exterior Brasileiro. São Paulo: Aduaneiras, 2000.

LUCENA, F. Lucena \& FILHO, S. Cosmo. Suprimento externo: uma abordagem técnica das práticas empresariais. João Pessoa: Editora Universitária/UFPB, 2002.

LUSTOSA, Leonardo. Planejamento e Controle da Produção. Elsevier Editora Ltda, 2008. $\mathrm{POZO}, \mathrm{H}$. Administração de recursos materiais e patrimoniais: uma abordagem logística. São Paulo: Atlas. 2004.

ROSENBLOOM, Bert. Canais de Marketing: uma visão gerencial. São Paulo: Atlas, 2002.

TAYLOR, D. Logística na cadeia de suprimentos: uma perspectiva gerencial. São Paulo, Pearson Addison-Wesley, 2005.

ReLAInEP - Revista Latino-America de Inovação e Engenharia de Produção, Curitiba, PR, Brasil, v. 3, n. 4, p. 153-169, 2015. 


\section{ReLAInEP}

\section{ANEXO I - Instruções Iniciais}

Questionário realizado para a busca de informações:

*Há quanto tempo a empresa está no mercado?

*Em que segmento a empresa atua? Quais os mercados que atendem?

*Quais os principais produtos?

*Como é definida a demanda, o cliente informa uma previsão de compras?

*Esta placa foi desenvolvida pela Safesoft, ou é realizada apenas a montagem conforme o projeto do cliente?

*Existe modificação no layout da placa periodicamente?

*Qual a quantidade do componente Rele 822 por placa (produto final)?

*Este componente possui similar?

*Como é realizada a busca por novos fornecedores?

*Qual o tempo de montagem desta placa?

* Mantém estoque mínimo do produto? E do item?

*Quanto antes do recebimento do componente a compra é disparada hoje?

* Este componente faz parte da montagem SMD ou PTH?

* Este componente influencia no teste de funcionamento da placa, ou ela pode ser testada sem este componente?

*Qual a finalidade (função) deste componente?

*Atualmente qual tipo de transporte é utilizado?

* Se a compra será feita na China e o produto é de origem Suíça, por que não será fechada a compra direta do fabricante?

* Já existe um planejamento de substituição (homologação) de algum item similar?

*Qual o processo de retirada do componente no posto de fiscalização (Brasil)?

* Quais custos estão inclusos na formação do preço do componente?

* Quais informações constam na DI?

*Existe alguma característica diferente no produto final conforme o cliente que solicita?

*Em que atividades o agente de cargas auxilia a montadora?

*Existe a possibilidade de falsificação deste componente? E como são tratados estes casos?

ReLAInEP - Revista Latino-America de Inovação e Engenharia de Produção, Curitiba, PR, Brasil, v. 3, n. 4, p. 153-169, 2015. 
ReLAInEP - Revista Latino-America de Inovação e Engenharia de Produção, Curitiba, PR, Brasil, v. 3, n. 4, p. 153-169, 2015. 